\title{
Initiation and expansion of layered fracture in sediments due to thermal-induced hydrate dissociation
}

\author{
X.H. Zhang *, X.B. Lu ${ }^{1}$ \\ Research Centre for Gas Hydrate and Soil Mechanics, Key Laboratory for Mechanics in Fluid-Solid Coupling System, Institute of Mechanics, Chinese Academy \\ of Sciences, Beijing 100190, China
}

\section{A R T I C L E I N F O}

\section{Article history:}

Received 2 August 2013

Accepted 19 March 2015

Available online 22 April 2015

\section{Keywords:}

hydrate-bearing sediment

hydrate dissociation

excess pore gas pressure

dissociation zone

layered fracture

\begin{abstract}
A B S T R A C T
Methane hydrate dissociation in sediment may lead to geological hazards such as marine landslide, collapse of wellbore. The physical mechanisms, especially on the evolution of sediment damage, are not very clear sediment though some numerical simulations were presented based on conventional landslide. A failure form, namely layered fracture in sediment, was observed in experiments during hydrate dissociation. It was a gap filled with gas and water formed from continuous sediment by the gas and water expansion. A large laterally distributed layered fracture in seabed is a potential mechanism for marine landslide formation due to the very small shear strength in the fracture. This issue was analyzed based on dimensionless method and a two-phase mathematical model. The extension of the method and results to relate the engineering problem were discussed also. A mathematical model for studying the initiation and expansion of layered fracture was presented first by decoupling the expansion of hydrate dissociation front, gas seepage, and the movement of soil layer. Then the critical condition for the initiation of layered fracture was obtained and the thickness expansion of the layered fracture was numerically analyzed. The results could be used to evaluate the development of layered fractures under the condition of different hydrate recovery methods and geo-mechanical properties of hydrate formations in the future and will be extended to the study on the mechanism of marine landslide.
\end{abstract}

(c) 2015 Elsevier B.V. All rights reserved.

\section{Introduction}

Hydrate is a crystalline ice-like solid compound composed of guest molecules such as methane, ethane, carbon dioxide, tetrahydrofuran (THF), sulfur dioxide, etc. and host water molecules. Gas hydrate, mainly methane hydrate, distributes in permafrost and marine sediments extensively under proper conditions of high pressure and low temperature (Sloan, 1998; Kvenvolden and Lorenson, 2001; Koh, 2002; Jones et al., 2007).

In hydrate exploration and exploitation, heat transfer leads to hydrate dissociation and the expansion of dissociation zone, accompanied by the seepage of pore gas and water and the deformation and movement of soils. Studies showed that the strength of hydrate-bearing sediment (HBS) reduces with hydrate dissociation due to the decrease of the cohesion between hydrate and soils and the increase of pore pressure (Winters et al., 2007; Waite et al., 2009; Zhang et al., 2012; Hyodo et al., 2014; Jiang et al., 2014; Song et al., 2014). An excess pore pressure could form without rapid drainage of pore gas and water, leading to the decrease of the

\footnotetext{
* Corresponding author. Tel.: +86 1082544192.

E-mail addresses: zhangxuhui@imech.ac.cn (X.H. Zhang), xblu@imech.ac.cn (X.B. Lu).

${ }^{1}$ Tel.: +861082544190 .
}

effective stress (Xu and Germanovich, 2006; Kwon et al., 2008). In consequence, environmental, geological hazards and structure damage such as a large volume of methane leakage, marine landslide, seabed subsidence, destruction of ocean platforms and wellbores etc. may occur (Xu and Germanovich, 2007; Lu et al., 2010, 2011). It was reported that the Storegga landslide on the Norwegian continental shelf, the largest landslide in the world involving 2500$3200 \mathrm{~km}^{3}$ sediments, was caused by thermal-induced hydrate dissociation (Bouriak et al., 2000; Sultan et al., 2004a, 2004b).

Layered fracture in sediments was discovered in thermal simulation of THF hydrate dissociation (Fig. 1) (Zhang et al., 2011). The physical process can be described as follows: excess pore pressure forms with hydrate dissociation, then continuous soil layer is cracked by the excess pore pressure accompanying the seepage of pore gas and water in hydrate dissociation zone and the motion of over layer (cap). In field conditions, layered fracture may form at four locations: in the production or exploration well, at the interface between the hydrate sediment and the cap, inside the dissociation zone, and inside the cap. Due to the excess pore pressure and zero shear strength of the layered fracture, sediment's deformation such as settlement, landslide etc., can occur, threatening the efficiency and safety of hydrate recovery.

One dimensional geo-mechanical and thermal responses of HBS subjected to thermal simulation were studied using geotechnical 


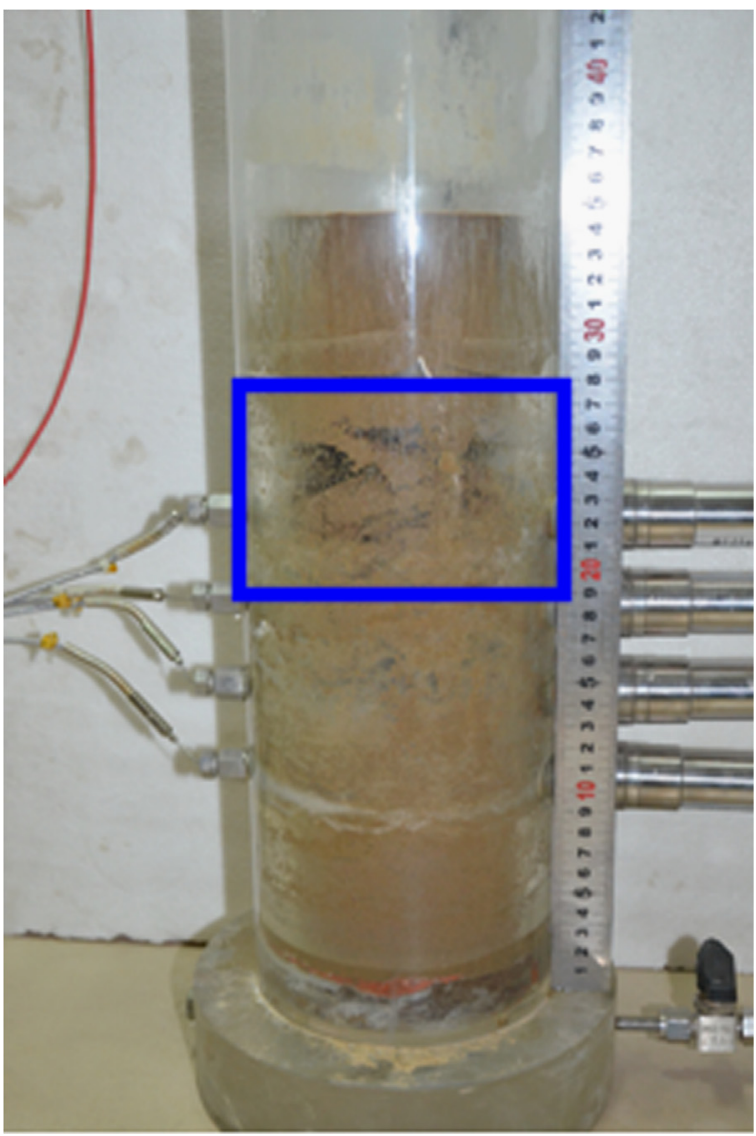

Fig. 1. Layered fracture.

centrifuge tests considering no fluid drainage. Layered fractures were observed in these tests (Kwon et al., 2013). Analytical models were presented for methane hydrate extraction and conventional marine landslide induced by natural thermal increase or pressure decrease, which coupled hydrate dissociation, gas/water flow, heat conduction, and soil deformation (Rutqvist and Moridis, 2009; Kimoto et al., 2010; Klar et al., 2010; Uchida et al., 2012). These models considered heat transfer, hydrate dissociation, fluid seepage and soil deformation with different soil constitutive models. The results showed that soil softening, settlement and shearing failure could occur accompanying hydrate dissociation expansion. However, these theoretical models are difficult to simulate the layered fracture in lack of the mechanism and experimental data.

THF hydrate is regarded as a good substitute for methane hydrate in experiments due to their similarities in mechanical and thermal properties. Meanwhile, a large volume of THF hydrate specimen is easily synthesized in a homogeneous status since THF is completely miscible with water in any proportion and forms hydrate at 1 atmosphere and $4{ }^{\circ} \mathrm{C}$ (Tohidi et al., 2001; Lee et al., 2007; Yun et al., 2007). So THF was adopted in the experiments.

The aim of this paper is to study the mechanism of layered fracture during heat-induced dissociation of hydrate sediment. A simplified formulation to analyze the critical condition and fracture expansion is presented first. Then the critical condition for the initiation of layered fracture is obtained and its expansion is discussed. The analytical results will be certificated by experiments.

\section{Physical description of layered fracture}

The process of layered fracture formation by heat-induced hydrate dissociation in sediments can be divided into two stages:

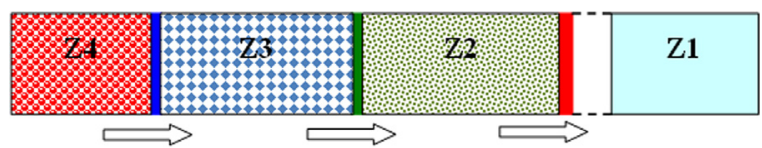

The arrow indicates the direction of seepage

Fig. 2. Physical process of layered fracture.

heat conduction in sediment and expansion of dissociation zone and formation of layered fracture.

\subsection{Heat conduction in sediment and expansion of dissociation zone}

Heat will conduct from thermal source when its temperature is higher than the surrounding. Heat conduction leads to hydrate dissociation once the phase equilibrium condition is destructed. Pores in sediment will then be filled with water, liquid THF (if it is THF hydrate) and gas (water vapor and gas THF) with hydrate dissociation and four different zones form, i.e. Z1-Non-dissociated zone, which consisted of hydrate and sediment skeleton; Z2Hydrate dissociation zone, which consisted of liquid, water and sediment skeleton; Z3-Gasification zone, which consisted of water, gas (gas THF in THF hydrate-bearing sediment) and sediment skeleton; Z4-Water vaporization zone, which consisted of gasification sediment skeleton, water vapor, gas THF (for THF hydrate); F1-Hydrate dissociation front; F2-Gasification front; F3-Water vaporization front (Zhang et al., 2010). Pore gas and water constrained in the dissociation zone induce excess pore pressure, which is the driving force of layered fracture because of the pressure difference between the dissociation zone and the environment or the fracture over it. The strength of the dissociation zone reduces greatly or even to zero due to the excess pore pressure and the decrease of cohesion of sediment. The resistance (due to soil gravity, soil shear strength and side friction) of the un-dissociated zone (cap) decreases with the expansion of dissociation zone; and its thickness becomes thinner and thinner (Zhang et al., 2011).

\subsection{Formation of layered fracture}

The released gas and water are constrained in the dissociation zone under low permeability conditions, so the effective stress of the dissociation zone reduces greatly and the total stress is supported by pore fluid. That means excess pore pressure forms. The pore pressure difference between the dissociation zone and the gas pushes the gap forward, i.e., the excess pore pressure is a driving force. Layered fracture initiates where the driving force equals or overcomes the resistance with the dissociation zone expanding to a critical value. The fracture becomes thicker with the seepage of gas from dissociation zones until a new force equilibrium achieves (Fig. 2). If the gas expansion energy is large enough to keep a continuous movement of the cap and to form more fractures, outburst (a phenomenon of gas, water and soil grains erupt) can occur (Zhang et al., 2011).

\section{Analysis of layered fracture formation and development}

7Zheng et al. (1993) studied the development of layered fracture and gas burst in coal bed. They described gas burst with two-phase (gas and grains) media theory. In this section, a similar mathematical model is presented to describe the formation and development of layered fracture after hydrate dissociation. Four phases, water, gas, hydrate and grains, are considered in this model.

The mass of each phase is determined by two effects, i.e., phase transformation in physical or chemical reaction and flow and mass transfer. So mass conservation equations of hydrate, gas, water, 
grains can be expressed as follows:

$\frac{\partial \varepsilon_{i} \rho_{i}}{\partial t}+\frac{\partial \varepsilon_{i} \rho_{i} v_{i}}{\partial x}=0$

in which $\varepsilon_{i}, \rho_{i}, v_{i}$ indicate the volume concentration, density and velocity, respectively, $i$ represents the gas $(\mathrm{g})$, water (w), hydrate (h) and sediment (s), $x, t$ are space coordinate and time coordinate, respectively.

Four forces are referred: inertial force, pore fluid pressure, drag force between the fluid and soil skeleton, and the gravity. According to Newton laws, momentum conservation equations of gas and water are as follows:

$\varepsilon_{j} \rho_{j} \frac{d v_{j}}{d t}+\varepsilon_{j} \frac{d p_{j}}{d x}=-H_{j}-\varepsilon_{j} \rho_{j} g$

Considering it as a one dimensional problem and assuming hydrate is part of the skeleton, the skeleton bears five kinds of forces, i.e., inertial force, effective stress between soils, drag force between fluid and skeleton and side friction, skeleton's gravity. Thus momentum equilibrium equation of the skeleton can be expressed as follows:

$\varepsilon_{s} \rho_{s} \frac{d v_{s}}{d t}+\frac{d \sigma_{e}}{d x}=H_{w}+H_{g}-\tau_{f} \frac{l}{A}-\varepsilon_{s} \rho_{s} g-\varepsilon_{h} \rho_{h} g$

in which, $j$ indicates gas and water, respectively, $p$ is the pore pressure, $H_{j}=\left(\varepsilon_{j}^{2} / k_{j}\right)\left(v_{j}-v_{s}\right)$ is the resistance between water and skeleton, gas and skeleton, $k_{j}$ is the physical permeability of gas and water corresponding to $j, \varepsilon_{j}$ is the volume fraction of gas or water, $\rho_{s}$ is the density of the skeleton, $\rho_{h}$ is the hydrate density, $v_{s}$ is the velocity of the skeleton, $\varepsilon_{s}$ is the volume percentage of the skeleton, $\varepsilon_{h}$ is the volume percentage of the hydrate, $\varepsilon_{g}$ is the concentration of the pore gas, $\varepsilon_{w}$ is the concentration of the pore water, $\sigma_{e}$ is the effective stress, $p_{g}$ is the pore gas pressure, $p_{w}$ is the pore water pressure, $H_{w}$ is the resistance between pore water and skeleton, $H_{g}$ is the resistance between pore gas and skeleton, $\tau_{f}(l / A)$ is the static side friction in unit length, $\tau$ is the static friction between soil and side wall, $l$ is the perimeter of side wall, and $A$ is the cross section area.

Substituting Eq. (2) to Eq. (3), the total momentum equilibrium of the four media can be expressed as follows:

$$
\begin{aligned}
& -\frac{\partial \sigma_{e}}{\partial x}-\varepsilon_{w} \frac{\partial p_{w}}{\partial x}-\varepsilon_{g} \frac{\partial p_{g}}{\partial x}-\varepsilon_{m} \rho_{m} g-\varepsilon_{w} \rho_{w} g-\varepsilon_{g} \rho_{g} g-\varepsilon_{h} \rho_{h} g \\
& \quad=\varepsilon_{m} \rho_{m} \frac{\partial v_{m}}{\partial t}+\varepsilon_{w} \rho_{w} \frac{\partial v_{w}}{\partial t}+\varepsilon_{g} \rho_{g} \frac{\partial v_{g}}{\partial t}+\tau_{f} \frac{l}{A}
\end{aligned}
$$

\subsection{Initiation of layered fracture}

It is observed in experiments that the movement of skeleton and pore fluids is so slow that the inertia effects could be neglected before initiation of layered fracture, then Eq. (4) can be simplified:

$-\frac{\partial \sigma_{e}}{\partial x}-\varepsilon_{w} \frac{\partial p_{w}}{\partial x}-\varepsilon_{g} \frac{\partial p_{g}}{\partial x}-\varepsilon_{m} \rho_{m} g-\varepsilon_{w} \rho_{w} g-\varepsilon_{g} \rho_{g} g-\varepsilon_{h} \rho_{h} g=\tau_{f} \frac{l}{A}$

In Zone I (as in Fig. 3), water and gas are non-existent. Integrating Eq. (5) to space $x$ in Zone I, and assuming the driving force (pore pressure) could overcome the resistance, the critical condition of layered fracture can be expressed as follows:

$p_{I}=\varepsilon_{g} p_{g}+\varepsilon_{w} p_{w}-p_{a} \geq \sigma_{t}+\varepsilon_{m} \rho_{m} g L+\varepsilon_{h} \rho_{h} g L+\frac{\tau_{f} l}{A} L$

in which $\sigma_{t}$ is the tensile strength of the soils, $p_{a}$ is the atmospheric pressure, $p_{I}$ is the character pore pressure, $L$ is the length of the moving part (in Fig. 3). The gravity terms in the above equation is considered when the failure happens in the vertical direction.

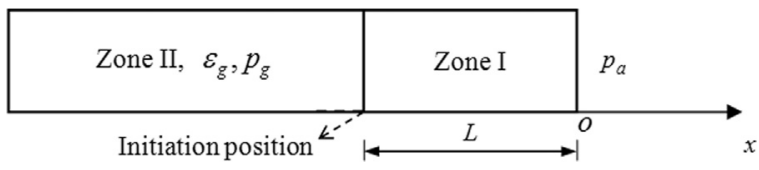

Fig. 3. Sketch of layered fracture.

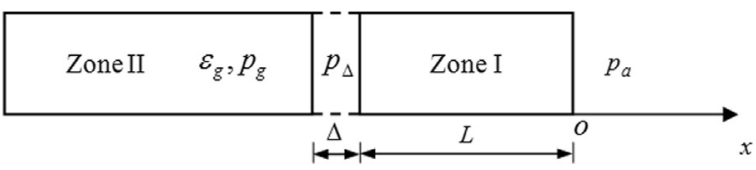

Fig. 4. Sketch of layered fracture expansion.

When the critical condition is exceeded, a micro crack forms at the interface of Zone I and Zone II (named initiation), and gas here drives Zone I upwards accompanying gas seepage from Zone II.

\subsection{Expansion of layered fracture}

The layered fracture expanses once it is initiated fracture. The pore pressure in the fracture decreases and so gas percolates into the fracture from Zone II. With the decrease of gas pressure in Zone II, new force equilibrium establishes, and layered fracture completes. The sketch of the model (Fractured zone: Zone I and Zone II) is shown in Fig. 4.

The viscosity of water is two orders of magnitude higher than gas; meanwhile the water occupies a very smaller pore space than gas, thus the water seepage is not considered here, and the gas volume fraction keeps constant. For the formulation of gas seepage, gas mass conservation, Darcy law and ideal gas status equation are used:

$\left\{\begin{array}{l}\frac{\partial \rho_{g}}{\partial t}+\frac{\partial \rho_{g} v_{g}}{\partial x}=0 \\ -\frac{\partial p_{g}}{\partial x}=\frac{\varepsilon_{g} \mu_{g}}{k_{g}} v_{g} \\ p_{g}=\frac{z \rho_{g} R T}{M_{g}}\end{array}\right.$

The initial and boundary conditions are as follows:

Initial conditions:

$t=0, \quad v_{g}=0, \quad p_{g}=p_{g 0}$

Boundary conditions:

$x=-h, \frac{\partial p_{g}}{\partial x}=0 ; \quad x=-L, p_{g}=p_{\Delta}$

in which, $z$ is the gas compressibility factor, $h$ is the thickness of the hydrate layer, $M_{g}$ is the mole mass of gas THF, $k_{g}, \mu_{g}, R, T, \varepsilon_{g}$ are the gas absolute permeability, viscosity, gas constant, temperature and gas volume fraction, respectively.

The flow rate $Q$ from Zone II into the fracture is

$Q=\varepsilon_{g 0} A \rho_{g} v_{g}$

The masses of the pore fluid $m$ in the fracture and the width of the fracture are as follows:

$m=m_{g}=m_{0 g}+\int_{0}^{t} Q d t$

$p_{\Delta}=\frac{m}{\Delta \cdot A \cdot M_{T H F} / R T}$

in which $p_{\Delta}$ is the pore pressure inside the fracture, $\Delta$ is the width of the fracture, $\Delta_{0}$ is the initial width of the fracture which is assumed as a small value just close to a pore length of $0.01 \mathrm{~mm}, m_{0 \mathrm{~g}}$ is the initial mass of pore gas in the fracture with width of $\Delta_{0}$. 
A1

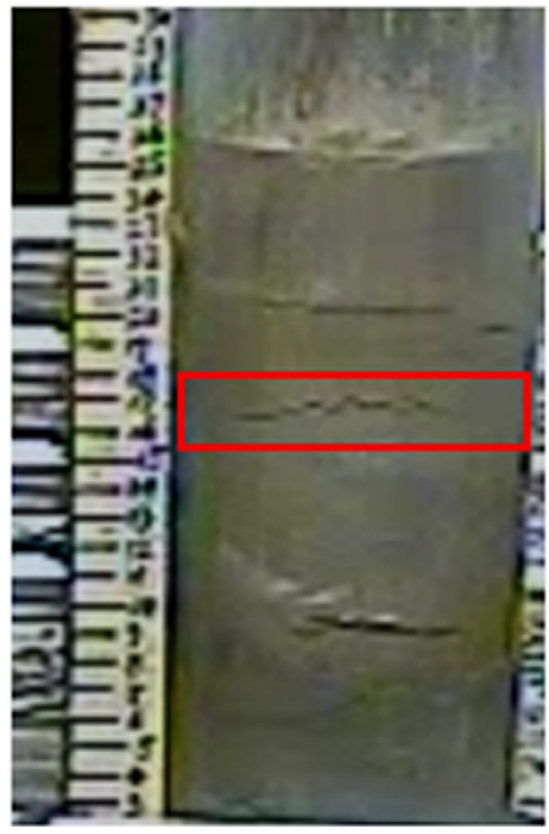

A4

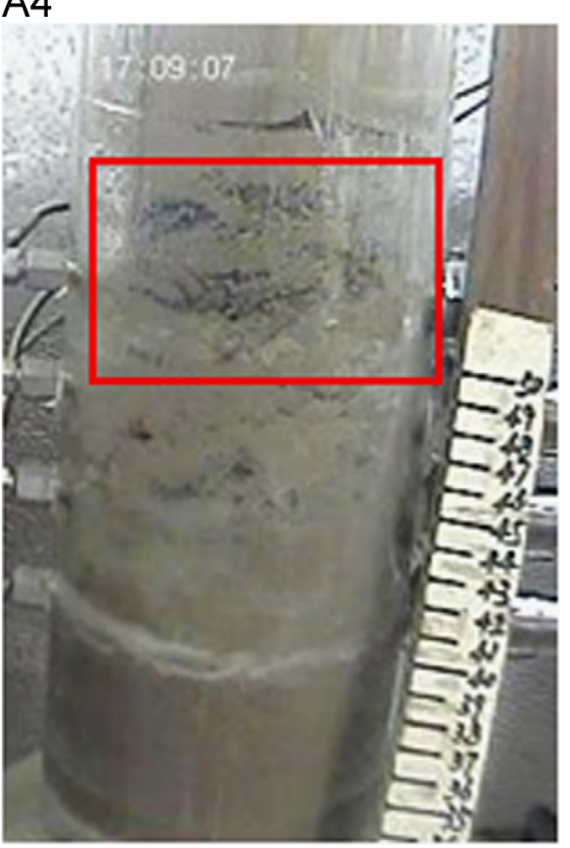

$\mathrm{A} 2$

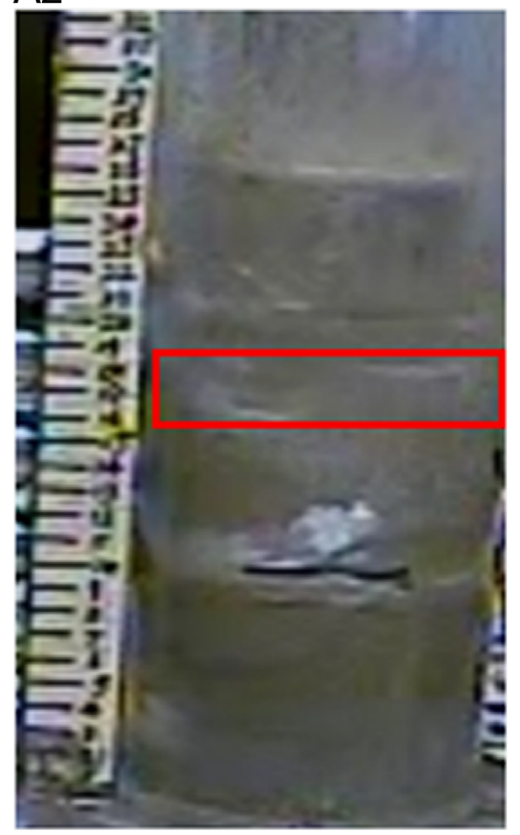

A5

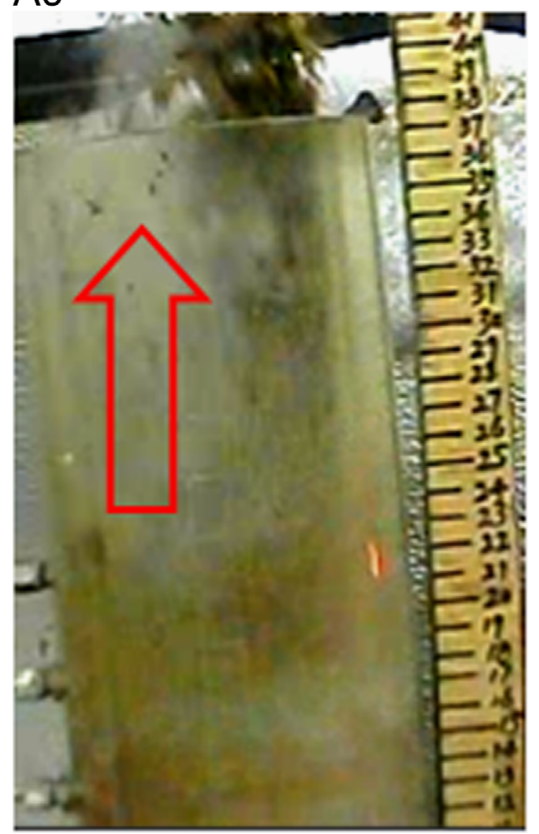

A3

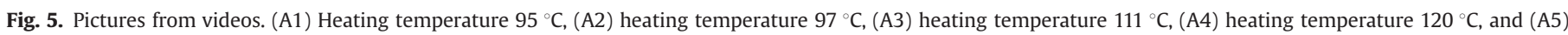
heating temperature $142{ }^{\circ} \mathrm{C}$.

THF gas volume consists of both the original unsaturated pore volume and that transferred from liquid THF to gas THF (the coefficient 0.9 is obtained from experiments of THF gas separation from THF-water solution). Then the gas volume fraction is expressed as follows:

$\varepsilon_{g 0}=\varepsilon_{0}\left(S_{a}+0.9 \frac{n_{g 0} M_{T H F} / \rho_{T H F}}{A(h-L) \varepsilon_{0}}\right)$

Substitute Eq. (13) into the ideal gas equation in Eq. (7), the gas molar number can be obtained:

$n_{g 0}=\varepsilon_{0} S_{a} /\left(\frac{R T}{p_{g 0} A(h-L)}-0.9 \frac{M_{T H F}}{\rho_{T H F} A(h-L)}\right)$

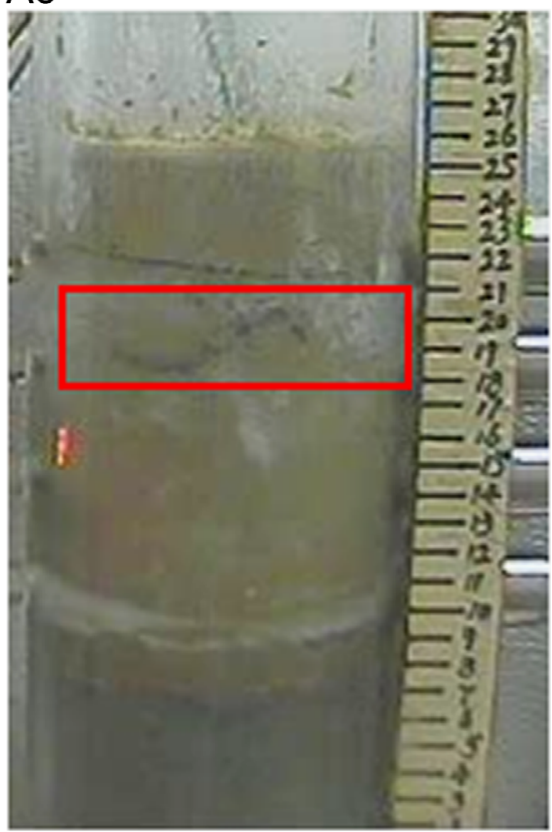

\section{.}

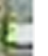

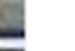

. 
according to Newton's second law, momentum conservation can be expressed as

The governing equation for cap movement:

$p_{\Delta}-p_{a}-\frac{\tau^{\prime \prime} l}{A} L-\bar{\rho} g L=\bar{\rho} L \cdot \ddot{\Delta}$

Initial conditions:

$t=0, \Delta=\Delta_{0}, \dot{\Delta}=0$

in which, $\tau^{\prime \prime}$ is the dynamic side friction. The above two equations indicate that the skeleton in Zone I will move in the right direction (Fig. 5) under the driving force once the fracture is initiated.

Through dimensional analysis, the characteristic time of seepage is obtained:

$t_{p}=\frac{\mu_{g} h^{2}}{k_{g} p_{0 g}} \approx 0.5 \mathrm{~s}$

The characteristic time of the cap movement is

$t_{m}=\sqrt{\frac{\Delta \cdot \rho_{s} \cdot h_{c}}{p_{0 g}}} \approx 0.005 \mathrm{~s}$

From Eqs. (18) and (19), the ratio between the characteristic time of these two physical process is $t_{p}: t_{m}=100: 1$. Thus decoupling method can be used in the simulation, i.e. seepage is calculated first in a time step $\Delta t$, the movement of the over layer is calculated immediately, and this process is repeated until the new static force equilibrium; this method will reduce cumulative errors and fasten the computational convergence.

The decoupling numerical simulation procedures are as follows:

Eqs. (7)-(10) are discretized using the central difference method in explicit scheme:

The governing equation for gas seepage is

$\left\{\begin{array}{l}\frac{\left(\rho_{g}\right)_{j}^{n+1}-\left(\rho_{g}\right)_{j}^{n}}{\Delta t}+\frac{\left(\rho_{g} v_{g}\right)_{j+1}^{n}-\left(\rho_{g} v_{g}\right)_{j-1}^{n}}{2 \Delta h}=0 \\ -\frac{\left(p_{g}\right)_{j+1}^{n}-\left(p_{g}\right)_{j-1}^{n}}{2 \Delta h}=\frac{\varepsilon_{g} \mu_{g}}{k_{g}}\left(v_{g}\right)_{j}^{n} \\ \left(p_{g}\right)_{j}^{n}=\frac{\left(\rho_{g}\right)_{j}^{n} R T}{M_{g}}\end{array} \quad j=1,2, \ldots, N\right.$

Initial conditions:

$\left(v_{g}\right)_{j}^{0}=0,\left(p_{g}\right)_{j}^{0}=p_{g 0}$

Boundary conditions:

$\left(p_{g}\right)_{0}^{n}=\left(p_{g}\right)_{1}^{n},\left(p_{g}\right)_{h-L}^{n}=\left(p_{\Delta}\right)^{n}$

Pore pressure in the fracture based on Eqs. (10)-(14):

$\left(p_{\Delta}\right)^{n}=\frac{m_{g 0}+\varepsilon_{g 0} A \sum_{k=0}^{n}\left(\rho_{g}\right)_{h-L}^{k}\left(v_{g}\right)_{h-L}^{k} \Delta t}{A(\Delta)^{n}} \cdot \frac{R T}{M_{T H F}}$

The gas volume fraction is calculated according to Eq. (15).

Eqs. (16) and (17) are discretized using the central difference method in implicit scheme:

Governing equation for the cap movement:

$\left(p_{\Delta}\right)^{n}-p_{a}-\frac{\tau^{\prime \prime} l}{A} L-\bar{\rho} g L=\bar{\rho} g \frac{(\Delta)^{n+1}-2(\Delta)^{n}+(\Delta)^{n-1}}{(\Delta t)^{2}}$

Initial conditions:

$(\Delta)^{0}=\Delta_{0}, \quad(\Delta)^{1}=(\Delta)^{0}$

in which, $j$ and $n$ represent the space and time step, respectively.

The gas seepage process is first computed according to the initial and boundary conditions in Eqs. (20)-(23). After a duration of $100 \cdot \Delta t$, the cap movement is computed by Eqs. (23)-(25). The processes go on similarly until new static force equilibrium is achieved.

\section{Results and discussion}

\subsection{Simple introduction of experimental set-ups and results}

Experiments were carried out in an organic glass cylinder with a size of inner diameter $10 \mathrm{~cm}$ and height $60 \mathrm{~cm}$ to model one dimensional condition. An immersion heater with power of $400 \mathrm{~W}$ and size of length $\times$ diameter $=10 \mathrm{~cm} \times 1 \mathrm{~cm}$ was vertically placed at $10 \mathrm{~cm}$ below the lower boundary of the cap since in such a onedimensional model the conditions and measurements can be controlled more accurately.

Sample preparation: Silty sand with specific gravity 2.65 , maximum void ratio 0.949 and minimum void ratio 0.454 was first compacted layer by layer to form the skeleton with a dry density of $1600 \mathrm{~kg} / \mathrm{m}^{3}$ and then saturated by THF-water solution with a mass fraction of $19 \%$ (in this fraction, THF and water can be totally consumed in hydrate formation). THF hydrate sediment was synthesized for 2-3 days at $1{ }^{\circ} \mathrm{C}$.

Experimental procedures: When the test started, the temperature of the heat source increased fast to the designed value in the first $2 \mathrm{~min}$, and then kept constant. The environmental temperature was kept at $1{ }^{\circ} \mathrm{C}$. Temperature and pressure evolution were measured by sensors vertically arranged in a $4 \mathrm{~cm}$ interval in the hydrate layer. It is noted that when the dissociation zone expanded to the place of pressure sensor, the fluid could percolate into and the pressure would be measured; meanwhile, the length of dissociation zone could be obtained. The temperature was measured to be about $4.4{ }^{\circ} \mathrm{C}$. With the expansion of dissociation zone, gas suddenly percolated into the interfaces of the dissociation zone and un-dissociated zone (over cap), pushed the cap and layered fracture initiated. All experiments were videotaped from which the expansion of the dissociation zone and the formation of layered fracture could be analyzed.

Five groups of experiments (Labelled as A1, A2, A3, A4 and A5) were carried out with different temperatures of the heat source. Different thick caps (Zone I in Fig. 4) saturated by $100 \%$ ice were set up. The side friction between cap and inner side of the model box is $0.18 \mathrm{MPa}$ measured by direct shearing test. The effects of temperature and cap thickness on the layered fracture were investigated. The experimental set-up and experimental results are listed in Table 1.

Fig. 5 presents the pictures obtained from the videos. The thicknesses of the layered fractures were measured by vernier caliper $(0.01 \mathrm{~mm})$ and straight scale $(\mathrm{cm})$. It should be noted that the thicknesses were approximately averaged due to curved interfaces of the layered fracture.

\subsection{Comparison of experimental and theoretical dissociation zone}

The measured dissociation zone of HBS before layered fracture is a little larger than the theoretical result because the skeleton's wetting zone by heated gas or water (it is noted that in this zone most of hydrate is not dissociated) was not distinguished from the dissociation zone (Table 2). The wetting zone increases with the temperature of heat source decreasing possibly because hydrate dissociates under lower temperature is slower, fluid seepage will induce thicker wetting zone, and the difference between the experimental and theoretical results increases.

\subsection{Verification of theoretical criterion of layered fracture}

Substituting experimental parameters (here, the thickness of the sediment over the dissociation zone in test is taken as the length $L$ (Table 2), the ambient pressure $p_{a}$, the tensile strength $\sigma_{t}$ and $l / A$ are $0.1 \mathrm{MPa}, 0 \mathrm{MPa}$ and $0.4 \mathrm{~cm}^{-1}$, respectively, the static side friction is $0.18 \mathrm{MPa}$ by direct shearing tests.) into Eq. (6), 
Table 1

Experimental conditions and results.

\begin{tabular}{|c|c|c|c|c|c|c|}
\hline Parameters & Units & A1 & A2 & A3 & A4 & A5 \\
\hline Heating temperature & ${ }^{\circ} \mathrm{C}$ & 95 & 97 & 111 & 120 & 143 \\
\hline Thickness of cap layer & $\mathrm{cm}$ & 5 & 5 & 5 & 5 & 5 \\
\hline Thickness of hydrate layer & $\mathrm{cm}$ & 10 & 10 & 10 & 20 & 20 \\
\hline Heating period before layered fracture & $\min$ & 51 & 69 & 54 & 109 & 101 \\
\hline Thickness of layered fracture & $\mathrm{cm}$ & 0.7 & 0.8 & 1.2 & 4 & $>6$ \\
\hline Experimental dissociation zone & $\mathrm{cm}$ & 10.5 & 11 & 10 & 20 & 21.5 \\
\hline Excess pore gas pressure & $\mathrm{MPa}$ & 0.24 & 0.20 & 0.31 & 0.38 & 0.70 \\
\hline Thickness of the sediment over layered fracture & $\mathrm{cm}$ & 8 & 7 & 8 & 8 & 6 \\
\hline
\end{tabular}

Note: When the temperature was $143^{\circ} \mathrm{C}$, the crack expanded so large that the cap was thrown out of the cylinder, and gas outburst occurred.

Table 2

Comparison of the experimental and theoretical dissociation zone.

\begin{tabular}{llcccc}
\hline Parameters & Units & A1 & A2 & A3 & A4 \\
\hline Heating temperature & ${ }^{\circ}$ C & 95 & 97 & 111 & 120 \\
Heating period before layered fracture & $\mathrm{min}$ & 51 & 69 & 54 & 109 \\
Experimental dissociation zone & $\mathrm{cm}$ & 10.5 & 11 & 10 & 73 \\
Theoretical dissociation zone & $\mathrm{cm}$ & 7.0 & 7.8 & 7.7 & 101 \\
\hline
\end{tabular}

corresponding to different thicknesses of the over caps, the ratios of driving force to resistance are 1.4, 1.4, 1.4, 1.2 MPa and 0.95, respectively, verifying the theoretical critical condition is practical.

\subsection{Verification of the expansion of layered fracture}

The parameters are adopted according to the experimental setup and materials introduced in Section 4.1:

$$
\begin{aligned}
& \rho_{s}= 1600 \mathrm{~kg} / \mathrm{m}^{3}, \varepsilon_{0}=0.4 S_{a}=0.2 \mu_{\mathrm{g}}=1.5 \times 10^{-5} \mathrm{~Pa} \mathrm{~s}, \quad k_{g}=1.0 \\
& \times 10^{-12} \mathrm{~m}^{2}, \\
& \rho_{T H F}=889 \mathrm{~kg} / \mathrm{m}^{3}, M_{T H F}=72 \mathrm{~g} / \mathrm{mol}, \quad R=8.31 \mathrm{~J} / \mathrm{mol} / \mathrm{k} .
\end{aligned}
$$

It is noted that the average dynamic side friction over the layered fracture is taken as $\tau^{\prime \prime}=0.025 \mathrm{MPa}$, about $14 \%$ that of static side friction (similar to the decreasing degree of shearing strength of hydrate sediment in Winters et al. (2007)). The thickness of the sediment over layered fracture is taken as the effective length $L$. Other parameters can be also referenced from the literature of Zhang et al. (2010). Figs. 6 and 7 show the evolution of gas pressure in the hydrate dissociation zone under the fracture with the heating temperature $95^{\circ} \mathrm{C}$ and the fracture thickness under different temperatures. A, B, C locate at the right end, $1 / 3$ from the right end and left end of Zone II, respectively (Fig. 4). The results show that the gas pressures at positions $\mathrm{A}, \mathrm{B}, \mathrm{C}$ decrease to a constant value (equals to the sum of the dynamic side friction and the cap's gravity) in about $0.2 \mathrm{~s}$. The expansion duration of the layered fracture was $0.5 \mathrm{~s}$ shorter than the numerical result.

Table 3 shows the comparison of experimental and theoretical fracture thickness. It can be seen that the decoupling method can be well used to evaluate the expansion of fracture thickness with dissociation of hydrate.

From the viewpoint of energy equilibrium, the fracture thickness is proportional to the energy ratio of released gas to the strength and gravity of the cap. When the energy of released gas increases to some extent while the energy of the strength and gravity of the cap is limited for a given case, gas outburst can occur.

\subsection{Engineering application of layered fracture}

To use the results in the above sections in an engineering application, a dimensionless analysis is conducted. The parameters

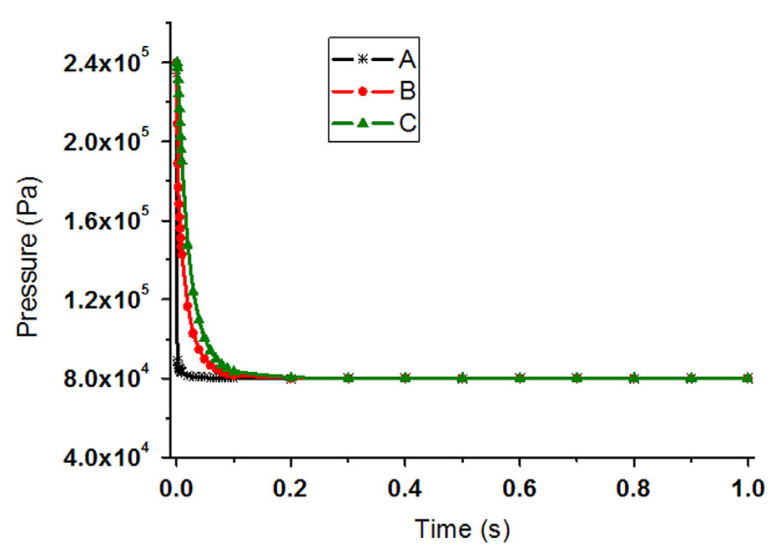

Fig. 6. Evolution of gas pressure in hydrate dissociation zone under fracture.

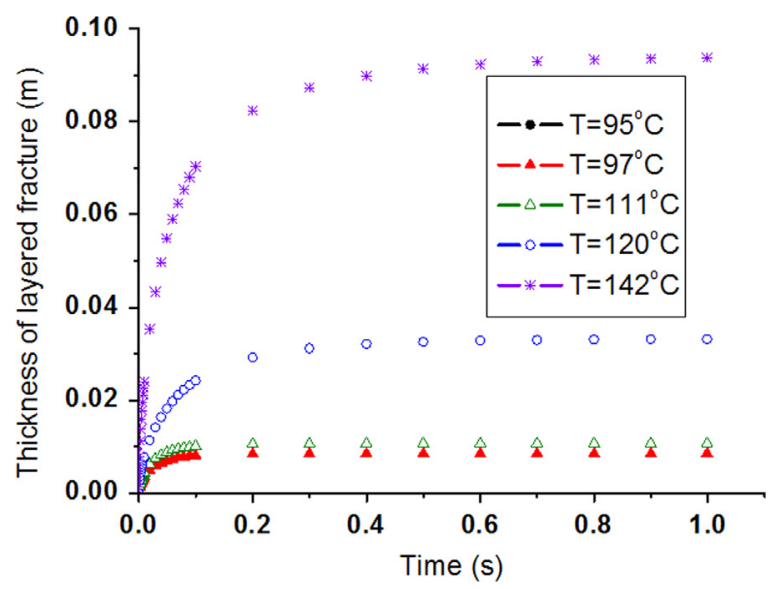

Fig. 7. The evolution of thickness of the fracture.

related with the initiation of layered fracture include the thickness of the total sediments $H$, the specific gravity of overlying layer $\bar{\rho} g$, the pressure above the overlying layer $p_{0}$, the excess pore gas pressure $p_{g}-p_{0}$, and the unit strength $\tau_{f} \cdot(l / A)$ of sediments over hydrate dissociation zone (when the shape is a circle with a radius 
Table 3

Comparison of the experimental and theoretical thickness of layered fracture.

\begin{tabular}{llcccc}
\hline Parameters & Units & A1 & A2 & A3 & A5 \\
\hline Heating temperature & ${ }^{\circ} \mathrm{C}$ & 95 & 97 & 111 & 120 \\
Experimental thickness of layered fracture & $\mathrm{cm}$ & 0.7 & 0.8 & 1.2 & 4 \\
Theoretical thickness of layered fracture & $\mathrm{cm}$ & 0.79 & 0.84 & 1.1 & 3.3 \\
\hline
\end{tabular}

of $R,(l / A)=(2 / R))$, and the thickness of hydrate dissociation zone $h$. It is assumed that the hydrate layer before hydrate dissociation is impermeable and the thickness of the soil layer is small.

Critical condition of layered fracture can be expressed as follows:

$f\left(h, H, \frac{\tau_{f} \cdot l}{A}, p_{g}, \bar{\rho} g, p_{0}\right)=0$

The dimensionless form of the above equation can be written as:

$f\left(\frac{h}{H}, \frac{\bar{\rho} g h}{p_{g}-p_{0}}, \frac{\tau_{f} \cdot l \cdot(H-h)}{A \cdot\left(p_{g}-p_{0}\right)}\right)=0$

in which, $h / H$ is the ratio of thickness of hydrate dissociation zone and thickness of total sediment during hydrate dissociation, $\bar{\rho} g h /\left(p_{g}-p_{0}\right)$ is the ratio of over soil layer gravity and excess pore pressure, $\tau_{f} \cdot l \cdot(H-h) / A \cdot\left(p_{g}-p_{0}\right)$ is the ratio of strength of the over soil layer (soil shearing strength or side friction) and excess pore pressure. If $h / H$ is large enough or $\bar{\rho} g h /\left(p_{g}-p_{0}\right)$ and $\tau_{f} \cdot l \cdot(H-h) / A \cdot\left(p_{g}-p_{0}\right)$ are small enough, layered fracture may occur. The dimensionless parameters control the initiation mechanism of layered fracture. If the above geometric and mechanical similar parameters in Eq. (27) can be the same in experiments as in practical engineering, the empirical Eq. (27) can be directly used in engineering application (it is noted that Eq. (27) can be transformed to Eq. (6) under the same condition). First, $h / H$ can be estimated theoretically or numerically based on different geometries of hydrate recovery, then when $\bar{\rho} g h /\left(p_{g}-p_{0}\right)$ and $\tau_{f} \cdot l \cdot(H-h) / A \cdot\left(p_{g}-p_{0}\right)$ are obtained, we can determine whether a formation of layered fracture occurs according to Eq. (27). The effects of pore pressure dissipation, the expansion of dissociation zone and soil deformation corresponding to different recovery methods on the speed of layered fracture will be studied further.

\section{Conclusions}

In this paper, the mechanism of layered fracture is illustrated. An analytical method is presented to formulate the formation of layered fracture.

The mechanism of layered fracture can be described as follows: heat transfer leads to phase-transitions i.e. solid-liquid-gas in sequence and the expansion of hydrate dissociation zone, accompanied by an excess pore gas pressure increase in the dissociation zone, and the effective stress and the side static friction of the undissociation zone decrease. The formation of layered fracture involves two key problems: critical condition and expansion. Once the driving force exceeds the resistance, the un-dissociation zone is initially moved, a fracture forms rapidly between two parts and the pore gas percolates into the fracture.

The critical condition has been obtained by static mechanical equilibrium. The expansion process has been formulated by decoupling the processes of gas seepage and sediment motion. The fracture thickness is proportional to the ratio of the energy of released gas to the sum of strength and gravity of the cap approximately.

The experimental results verify the theoretical results in both the criterion and thickness of layered fracture. The positions of the layered fracture and damage degree are determined by some unstable physical mechanisms, which will be studied in the future.

\section{Acknowledgments}

This study is supported by the National Natural Science Foundation of China (Nos. 11102209, 51239010, and 11272314). And many thanks to professor Ming Xiao from The Pennsylvania State University for revising the language of the paper.

\section{References}

Bouriak, S., Vanmste, M., Saoutkine, A., 2000. Inferred gas hydrates and clay diapers near the Storegga slide on the southern edge of the V $\varphi$ ring Plateau, offshore Norway. Mar. Geol. 163, 125-148.

Hyodo, M., Li, Y.H., Yoneda, J., 2014. Effects of dissociation on the shear strength and deformation behavior of methane hydrate-bearing sediments. Mar. Pet. Geol. $51,52-62$.

Jiang, M.J., Chen, H., Tapias, M., 2014. Study of mechanical behavior and strain localization of methane hydrate bearing sediments with different saturations by a new DEM model. Comput. Geotech. 57, 122-138.

Jones, K.W., et al., 2007. Microstructure of natural hydrate host sediments. Nucl. Instrum. Methods Phys. Res. B 261, 504-507.

Kvenvolden, K.A., Lorenson, T.D., 2001. The global occurrence of natural gas hydrate. Geophys. Monogr. 124, 3-18.

Koh, C.A., 2002. Towards a fundamental understanding of natural gas hydrates. Chem. Soc. Rev. 31, 157-167.

Kwon, T.H., Cho, G.C., Santamarina, J.C., 2008. Gas hydrate dissociation in sediments: pressure-temperature evolution. Geochem. Geophys. Geosyst. 9, Q03019. http://dx.doi.org/10.1029/2007GC001920.

Kimoto, S., Oka, F., Fushita, T., 2010. A chemo-thermo-mechanically coupled analysis of ground deformation induced by gas hydrate dissociation. Int. J. Mech. Sci. 52, 365-376.

Klar, A., Soga, K., Ng, M.Y.A., 2010. Coupled deformation-flow analysis for methane hydrate extraction. Geotechnique 60 (10), 765-776.

Kwon, T.H., Oh, T.M., Choo, Y.W., et al., 2013. Geomechanical and thermal responses of hydrate bearing sediments subjected to thermal simulation: physical modeling using a geotechnical centrifuge. Energy Fuels 27, 4507-4522.

Lee, J.Y., Yun, T.S., Santamarina, J.C., Ruppel, C., 2007. Observations related to tetrahydrofuran and methane hydrates for laboratory studies of hydratebearing sediments. Geochem. Geophys. Geosyst 8 (6), Q06003.

Lu, X.B., Wang, L., et al., 2010. Instability of seabed and pipes induced by NGH dissociation. In: Proceedings of the 20th International Offshore and Polar Engineering Conference (ISOPE). Beijing, pp. 110-114.

Lu, X.B., Zhang, X.H., Wang, S.Y., 2011. Strong failure of seabed induced by gas hydrate dissociation. In: Proceedings of the 7th International Conference on Gas Hydrate. Edinburgh.

Rutqvist, J., Moridis, G.J., 2009. Numerical studies on the geomechanical stability of hydrate-bearing sediments. SPE J. 14 (2), 267-282. http://dx.doi.org/10.2118/ 126129-PA SPE-126129-PA.

Sloan, E.D., 1998. Clathrate Hydrates of Natural Gases. Marcel Dekker Inc., New York.

Song, Y.C., Yang, L., Zhao, J.F., 2014. The status of natural gas hydrate research in China: a review, Renew. Sustain Energ Rev. 31, 778-791.

Sultan, N., et al., 2004a. Dynamics of gas hydrate: case of Congo continental slope. Mar. Geol. 206, 1-18.

Sultan, N., et al., 2004b. Effect of gas hydrates melting on seafloor slope instability. Mar. Geol. 213, 379-401.

Tohidi, B., et al., 2001. Visual observation of gas hydrate formation and dissociation in synthetic porous media by means of glass micromodels. Geology 29 (9), 867-870.

Uchida, S., Soga, K., Klar, A., Yamamoto, K., 2012. Geomechanical study of the Mallik gas hydrate production field trials. Bull. Geol. Surv. Can. 601, 191-204.

Winters, W.J., Waite, W.F., Mason, D.H., et al., 2007. Methane gas hydrate effect on sediment acoustic and strength properties. J. Pet. Sci. Eng. 56, 127-135.

Waite, W.F., et al., 2009. Physical properties of hydrate-bearing sediments. Rev. Geophys. 47, 1-38, RG4003/2009.

Xu, W., Germanovich, L.N., 2006. Excess pore pressure resulting from methane hydrate dissociation in marine sediments: a theoretical approach. J. Geophys. Res. 111, B011104. http://dx.doi.org/10.1029/2004JB003600.

Xu, W., Germanovich, L.N., 2007. Reply to comment by Nabil Sultan on "Excess pore pressure sesulting from methane hydrate dissociation in marine sediments: a 
theoretical approach". J. Geophys. Res. 112, B02104. http://dx.doi.org/10.1029/ 2006JB004722.

Yun, T.S., Santamarina, J.C., Ruppel, C., 2007. Mechanical properties of sand, silt, and clay containing tetrahydrofuran hydrate. J. Geophys. Res. 112, B04106.

Zhang, X.H., Lu, X.B., Li, Q.P., Yao, H.Y., 2010. Thermally induced evolution of phase transformations in gas hydrate sediment. Sci. China Phys., Mech. Astron. 53 (8), 1-6. http://dx.doi.org/10.1007/s11433-010-4060-8.
Zhang, X.H., Lu, X.B., Li, Q.P., 2011. Formation of layered fracture and outburst during gas hydrate dissociation. J. Pet. Sci. Eng. 76 (3-4), 212-216.

Zhang, X.H., Lu, X.B., Zhang, L.M., Wang, S.Y., Li, Q.P., 2012. Experimental study on mechanical properties of methane-hydrate-bearing sediments. Acta Mech. Sin. 28 (5), 1-11.

Zheng, Z.M., Chen, L., Ding, Y.S., 1993. Steady advance of damage front during one dimensional gas burst. Sci. China A 23 (4), 723-730. 